\title{
Cellular and Behavioral Outcomes of Dorsal Striatonigral Neuron Ablation: New Insights into Striatal Functions
}

\author{
Delphine Révy',5, Florence Jaouen 1,5, Pascal Salin', Christophe Melon', Dorian Chabbert', \\ Elisiana Tafi ${ }^{2}$, Lena Concetta ${ }^{2}$, Francina Langa ${ }^{3}$, Marianne Amalric ${ }^{4}$, Lydia Kerkerian-Le Goff', \\ Hélène Marie ${ }^{2,6}$ and Corinne Beurrier*,I \\ 'Institut de Biologie du Développement de Marseille (IBDM), Aix-Marseille University (AMU), Centre National de la Recherche Scientifique \\ (CNRS), UMR 7288, Marseille Cedex 9, France; ${ }^{2}$ The European Brain Research Institute, Roma, Italy; ${ }^{3}$ Institut Pasteur, Mouse Genetics \\ Engineering Center, Paris Cedex 15, France; ${ }^{4}$ Laboratoire de Neurosciences Cognitives, Aix-Marseille University, Centre National de la \\ Recherche Scientifique (CNRS), UMR 729I, Marseille Cedex 3, France
}

The striatum is the input structure of the basal ganglia network that contains heterogeneous neuronal populations, including two populations of projecting neurons called the medium spiny neurons (MSNs), and different types of interneurons. We developed a transgenic mouse model enabling inducible ablation of the striatonigral MSNs constituting the direct pathway by expressing the human diphtheria toxin (DT) receptor under the control of the Slc35d3 gene promoter, a gene enriched in striatonigral MSNs. DT injection into the striatum triggered selective elimination of the majority of striatonigral MSNs. DT-mediated ablation of striatonigral MSNs caused selective loss of cholinergic interneurons in the dorsal striatum but not in the ventral striatum (nucleus accumbens), suggesting a regionspecific critical role of the direct pathway in striatal cholinergic neuron homeostasis. Mice with DT injection into the dorsal striatum showed altered basal and cocaine-induced locomotion and dramatic reduction of L-DOPA-induced dyskinesia in the parkinsonian condition. In addition, these mice exhibited reduced anxiety, revealing a role of the dorsal striatum in the modulation of behaviors involving an emotional component, behaviors generally associated with limbic structures. Altogether, these results highlight the implication of the direct striatonigral pathway in the regulation of heterogeneous functions from cell survival to regulation of motor and emotion-associated behaviors.

Neuropsychopharmacology (20I4) 39, 2662-2672; doi:I0.1038/npp.20I4.I2I; published online 9 July 2014

\section{INTRODUCTION}

The basal ganglia (BG) are key neural substrates that control motor and reward-associated behaviors. Their dysfunction is associated with several disorders, including Parkinson's disease (PD), schizophrenia, and drug addiction (Cenci, 2007; Graybiel, 2000; Lobo and Nestler, 2011). As the main $\mathrm{BG}$ input, the striatum is thought to be an important site for mediating many of the maladaptive processes responsible for these devastating neurological disorders.

The striatum is classically delineated into dorsal (dorsal striatum) and ventral (nucleus accumbens) territories,

\footnotetext{
*Correspondence: Dr C Beurrier, Institut de Biologie du Développement de Marseille (IBDM), Aix-Marseille University (AMU), Centre National de la Recherche Scientifique (CNRS), UMR 7288, Parc Scientifique de Luminy, Case 907, Marseille 13288, France, Tel: + 33 49I 2692 48, Fax: + 33 49I 2692 44,

E-mail: corinne.beurrier@univ-amu.fr

${ }^{5}$ These authors contributed equally to this work.

${ }^{6}$ Current address: Institut de Pharmacologie Moléculaire et Cellulaire (IPMC), Université de Nice Sophia Antipolis, Centre National de la Recherche Scientifique (CNRS), UMR 7275, Valbonne 06560, France. Received 2 December 2013; revised 18 April 2014; accepted 16 May 2014; accepted article preview online 6 June 2014
}

involved in cognitive/motor and emotional/motivational functions, respectively. However, interconnections and other crosstalk, in particular involving the dopamine systems, provide an anatomical basis for a multifunctional interface (Haber et al, 2000). The dorsal striatum receives heavy dopaminergic input from the substantia nigra pars compacta ( $\mathrm{SNc}$ ), and dysfunction of dopamine signaling is implicated in almost all BG-associated disorders. The major striatal targets of dopamine afferents are the GABAergic medium spiny neurons (MSNs) which constitute $95 \%$ of the striatal population. The remaining neurons, comprising approximately $5 \%$ of the total number of striatal neurons, are made up of different subtypes of GABAergic interneurons and of cholinergic interneurons. Despite being few in number, cholinergic interneurons are crucial for the tuning of striatal output owing to their dense terminal fields primarily directed to the two populations of MSNs that overlap those of dopaminergic neurons (Bolam et al, 1984). The two types of MSNs are distinguished depending on their projections and expression of distinct set of proteins. MSNs that project primarily to the substantia nigra pars reticulata $(\mathrm{SNr})$, so-called direct-pathway or striatonigral MSNs, express the dopamine $\mathrm{D}_{1}$ receptor, substance P (SP) and dynorphin, whereas MSNs that project to the globus 
pallidus (GP), so-called indirect or striatopallidal MSNs, express the dopamine $\mathrm{D}_{2}$ receptor and enkephalin (Enk) (Gerfen et al, 1990; Smith et al, 1998). Because of the differential expression of dopamine receptors, the striatonigral and striatopallidal MSNs are thought to have opposing but balancing roles on BG output and behaviors (Albin et al, 1989; DeLong, 1990).

Recent advances in cell-type-specific technologies have provided a wealth of data allowing a more comprehensive understanding of MSNs roles in drug addiction (Durieux et al, 2009; Durieux et al, 2012; Ferguson et al, 2011; Lobo et al, 2010), cognitive functions (Hikida et al, 2010; Hikida et al, 2013; Nishizawa et al, 2012; Tai et al, 2012; Yawata et al, 2012), and parkinsonian physiopathology (Kravitz et al, 2010). Here, we developed a new inducible model of diphtheria toxin (DT) receptor-mediated ablation to further explore the functional implications of striatonigral MSNs of the dorsal striatum. For behavioral characterization, we first focused on motor function linked to disturbed striatal dopamine tone, cocaine-induced locomotion, and L-DOPA-induced dyskinesia (LID), which are associated with selective and robust molecular changes in striatonigral MSNs, including ERK signaling (BertranGonzalez et al, 2008; Santini et al, 2009). Acute response to psychostimulant has been investigated using amphetamine in a model of striatonigral MSNs ablation restricted to subterritories of the dorsal striatum (Durieux et al, 2012), and direct demonstration of dorsal striatonigral MSNs involvement in LID, a major complication of the most common pharmacotherapy of $\mathrm{PD}$, is still lacking. We next moved to non-motor function as accumulating evidence suggests that, in addition to sensorimotor information processing, the dorsal striatum might also mediate emotional/motivational functions classically ascribed to the ventral striatum (Balleine et al, 2007). We focused on anxiety behavior, notably because SP and dynorphin, two molecules released by striatonigral MSNs, have been implicated in the regulation of anxiety (Ebner and Singewald, 2006; Van't Veer and Carlezon, 2013).

The results show that ablation of striatonigral MSNs impacts heterogeneous functions from motor- and emotional-associated behaviors to region-specific regulation of cholinergic homeostasis.

\section{MATERIALS AND METHODS}

\section{Generation of Transgenic Mice}

The human Diphtheria Toxin Receptor-green fluorescent protein (DTR-GFP) cDNA was inserted in front of the endogenous ATG in exon 1 of the Slc35d3 gene in a 196kilobase mouse bacterial artificial chromosome (BAC) (RP23-344M6) by homologous recombination using the recombineering plasmid pL451. DNA from the modified BAC was purified and microinjected into pronuclei of fertilized mouse eggs (B65JL/F1) to generate transgenic founders (Mouse Genetics Engineering Center, Institut Pasteur). A total of five transgene-positive founders were obtained and were bred with $\mathrm{C} 57 \mathrm{Bl} / 6$ mice. Offspring consisted of an equal number of DTR-expressing mice $\left(\mathrm{DTR}^{+}\right)$and of DTR non-expressing mice (DTR $\left.{ }^{-}\right)$.

\section{Stereotaxic Injections}

All animal experimental procedures were carried out in strict accordance with local rules concerning the use of laboratory animals (authorization no.B 13-464) and with the recommendations of the EEC (2010/63/UE) for care and use of laboratory animals and conformed to the ethical guidelines of the French Ministry of Agriculture and Forests (Animal Health and Protection Veterinary Service).

Surgery was performed on 8-12 week-old mice under xylazine/ketamine anesthesia (intraperitoneal injections, 10 and $100 \mathrm{mg} / \mathrm{kg}$, respectively). All stereotaxic coordinates are listed in Supplementary Table S1. DT, (Calbiochem, Darmstadt, Germany) was diluted to a concentration of $0.5 \mathrm{ng} / \mu \mathrm{l}$, and $1 \mu \mathrm{l}$ was injected at two sites either into the dorsal striatum or into the nucleus accumbens. For retrograde tracing, $1 \mu \mathrm{l}$ of fluorescent microbeads (Life Technologies, Saint-Aubin, France) were injected into the SNr. For dopaminergic lesion, mice received one unilateral injection $(1.5 \mu \mathrm{l})$ of 6-hydroxydopamine hydrochloride (6-OHDA; $2.7 \mu \mathrm{g} / \mu \mathrm{l}$; diluted in $0.9 \%$ sterile $\mathrm{NaCl}$ containing $0.1 \%$ ascorbic acid; Sigma-Aldrich, St QuentinFallavier, France) into the SNc.

\section{Quantitative In Situ Hybridization and Dopamine Transporter Autoradiography}

Radioactive in situ hybridization histochemistry was performed as described previously (Salin et al, 2002). Probes were 44-56 mer synthetic oligonucleotides selected on the basis of the sequence of Tacl (which encodes SP; hereafter called SP), Penk (which encodes Enk; hereafter called Enk), GAD 67, and tyrosine hydroxylase $(T H)$ and were $3^{\prime}$-end-labeled by terminal deoxynucleotide transferase with ${ }^{35} \mathrm{~S}$-dATP. ${ }^{3} \mathrm{H}$-mazindol was used as a ligand to label dopamine transporter sites. Briefly, after appropriate washes, sections were incubated with $15 \mathrm{nM}\left[{ }^{3} \mathrm{H}\right]$-mazindol (DuPont NEN Research Products, Boston, MA; specific activity, $17 \mathrm{Ci} / \mathrm{mmol}$ ) in a Tris buffer containing $0.3 \mathrm{mM}$ desipramine to block the noradrenalin uptake sites.

\section{Quantitative RT-PCR}

The uninjected and injected dorsal striatum of three DTR ${ }^{+}$ mice injected with DT into the dorsal striatum were punched separately. Specific primers for the different genes of interest were designed using the Universal ProbeLibrary (ProbeFinder version 2.5 for mouse, Roche Diagnostics) and chosen intron-spanning when possible (Supplementary Table S2). Total RNA (170 ng) was reverse transcribed for $5 \mathrm{~min}$ at $25^{\circ} \mathrm{C}, 30 \mathrm{~min}$ at $42{ }^{\circ} \mathrm{C}$ and $5 \mathrm{~min}$ at $85^{\circ} \mathrm{C}$ using iScript Reverse Transcription Supermix for RT-qPCR (BIORAD). A Bio-Rad CFX96 cycler was used with the following cycling parameters: 1 cycle at $95^{\circ} \mathrm{C}$ for $8 \mathrm{~min}, 40$ cycles at $95^{\circ} \mathrm{C}$ for $15 \mathrm{~s}$ followed by $60^{\circ} \mathrm{C}$ for $1 \mathrm{~min}$. Samples were run in three replicates for each gene. Relative target gene concentration was calculated using the $2^{-\Delta \Delta \mathrm{Ct}}$ method (Livak and Schmittgen, 2001), which uses normalization to $\beta$-actin endogenous reference gene (as described in Lobo et al, 2006) and normalization to calibrator sample (here, uninjected dorsal striatum side). 


\section{Dual Fluorescence In Situ Hybridization}

Two-color fluorescent in situ hybridization was performed with a mixture of fluorescein-labeled antisense riboprobe for ChAT or SP and a digoxigenin-labeled riboprobe for DTR. After appropriate pretreatments, sections were incubated at $65^{\circ} \mathrm{C}$ overnight in the hybridization mix containing $400 \mathrm{ng} / \mathrm{ml}$ of both probes. After posthybridization washes, sections were incubated for $5 \mathrm{~h}$ with anti-Fluorescein-POD (HRP) (1/300) (Roche-Applied Science), and the fluorescein probe was visualized in green with fluorescein-tyramide reagent (TSA Plus PerkinElmer Life Sciences). After inactivating the HRP conjugate of the anti-FluoresceinPOD antibody $\left(3 \% \mathrm{H}_{2} \mathrm{O}_{2}\right)$, the digoxigenin probe was then visualized in red with anti-digoxigenin-POD antibody (1/300) followed by cyanine-3-tyramide reagent.

\section{Immunohistochemistry}

Mice were perfused transcardially with ice-cold $4 \%$ paraformaldehyde in $0.1 \mathrm{M}$ phosphate-buffered saline (PBS, $\mathrm{pH}$ 7.4). After overnight postfixation, brains were protected in a PBS solution containing 30\% sucrose and frozen. Cryostat sections $(40 \mu \mathrm{m})$ were incubated overnight at $4{ }^{\circ} \mathrm{C}$ with primary antibodies and then incubated with the appropriate secondary antibodies (Supplementary Table S3).

\section{Data Analysis}

Analysis of DT-mediated effects in the striatum was performed on 4-6 coronal sections per animal extending from $\mathrm{AP}=+1.54$ to 0.14 relative to bregma according to the mouse stereotaxic brain atlas of Paxinos and Franklin (Second edition, 2001).

\section{Single-Cell RT-PCR}

Coronal striatal slices $(250 \mu \mathrm{m})$ from $\mathrm{DTR}^{+}$mice were prepared and recorded as previously described (Beurrier et al, 2009). After cell-attached and whole-cell recordings, the cell content was aspirated, expelled into a test tube where the RT reaction was performed overnight at $40{ }^{\circ} \mathrm{C}$. The single-cell RT-PCR protocol used here was adapted from Lena et al (1999) to simultaneously detect the expression of DTR-GFP and ChAT mRNAs. Genomic DNA amplification was systematically assessed using a NMDA receptor gene intron (NR1 subunit, GRIN1) as genomic control (Supplementary Table S4). The cDNAs were first amplified by 20 PCR cycles $\left(94{ }^{\circ} \mathrm{C}, 1 \mathrm{~min} ; 60^{\circ} \mathrm{C}, 1 \mathrm{~min} ; 72^{\circ} \mathrm{C}, 1 \mathrm{~min}\right)$ using $5 \mathrm{U}$ of Taq polymerase (Qiagen, Hilden, Germany), and 10 pmol of different sets of primers (Supplementary Table S3) were added (final volume, $100 \mu \mathrm{l}$ ). Second rounds of PCR (40 cycles as described above) were then performed using $6 \mu \mathrm{l}$ of the first PCR product as a template (final volume $50 \mu \mathrm{l})$. Each cDNA was amplified individually using its specific primer generating PCR fragments of 406, 323 and 162 bp for DTR-GFP, ChAT and GRIN1 introns, respectively.

\section{Behavioral Tests}

Mice were group-housed (2-5 mice/cage) and maintained on a $12: 12$-h light-dark cycle ( 0700 hours lights on) with ad libitum food and water available.
Locomotor activity. Locomotor activity was monitored in individual activity chambers $(11.2 \mathrm{~cm} \times 20.7 \mathrm{~cm})$ housed within a sound-attenuating cubicle and under homogenous light illumination (Imetronic, Pessac, France). Each chamber was equipped with four infrared photobeams located $1.5 \mathrm{~cm}$ above floor level, two at the rear and two at the front of the chamber. Mice were given i.p. injections of saline $(0.9 \% \mathrm{NaCl})$ for the first 3 testing days to habituate them to the injections, handling, and activity chambers. On the fourth day, mice of each genotype were divided into two groups receiving either i.p. injections of saline $(0.9 \% \mathrm{NaCl})$ or cocaine hydrochloride (5 or $15 \mathrm{mg} / \mathrm{kg}$; Sigma-Aldrich). Locomotor activity was monitored immediately afterwards for $60 \mathrm{~min}$. The number of beam breaks was recorded in 5-min bins.

L-DOPA-induced dyskinesia. Mice received unilateral DT injection into the dorsal striatum ipsilateral to the 6-OHDAinjected side. Fifteen days later, they received a single daily injection of L-DOPA $(20 \mathrm{mg} / \mathrm{kg})$ and benserazide hydrochloride $(10 \mathrm{mg} / \mathrm{kg})$ for 21 days. The abnormal involuntary movements (AIMs) were assessed by two investigators blind of subject genotype for $1 \mathrm{~min}$ every $20 \mathrm{~min}$ from 20 to $120 \mathrm{~min}$ after the last injection on day 21. Axial, limb, and orolingual AIMs were scored using a previously established scale from 0 to 4 for each AIM subtype (Lundblad et al, 2004), and the sum of the three scores, defined as dyskinesia score, was determined for each animal (maximal score, 12). Locomotive AIM was expressed as the number of contralateral rotations per minute for each animal.

Open field. The open-field chamber $\left(50 \times 50 \mathrm{~cm}^{2}\right.$ with a $30 \mathrm{~cm}$-high white plastic wall) was virtually divided into a central field (center, $25 \times 25 \mathrm{~cm}^{2}$ ) and an outer field (periphery). The open-field test consisted of a 5-min session and was conducted under dim lighting conditions (12 Lux). Individual mice were placed in the center of the field, and the paths of the animals were recorded by a video camera. The distance traveled in the different zones was analyzed by a video-tracking software (Viewpoint Life Sciences, Lyon, France).

Elevated plus maze. The apparatus is elevated $50 \mathrm{~cm}$ above the floor and consisted of four arms $(6 \mathrm{~cm} \times 37 \mathrm{~cm})$, two enclosed by $18 \mathrm{~cm}$-high white plastic walls and two open. Light intensity was 12 Lux in open arms and 4 Lux in closed arms. Each trial began with the placement of the mouse in the maze center, facing an open arm. The paths of the animals were recorded for $5 \mathrm{~min}$ by a video camera. The distance traveled and the numbers of entries in the open and closed arms were quantified by a video-tracking software (Viewpoint Life Sciences). Mice were tested in the levated plus maze 1 day after the open-field test.

\section{Statistical Analysis}

Data are presented as mean \pm SEM. Statistical analyses (SigmaStat, v3.1) were performed using the unpaired Student's $t$-test. A nonparametric test (test of MannWhitney) was used if the normality or equal variance test failed. Two-way repeated-measured ANOVA followed by 
Holm-Sidak post tests was used for analyzing time profiles of AIM scores. A significance of $p<0.05$ was required for rejection of the null hypothesis.

\section{RESULTS}

\section{Generation of Slc35d3 $3^{\text {DTR-GFP }}$ Transgenic Mice}

To ablate striatonigral MSNs, we used the human DTR, the activation of which by DT induces cell apoptosis. We first checked the ability of the fusion DTR-GFP construct to induce cell death in vitro. In wild-type cultured hippocampal neurons expressing DTR-GFP fusion, administration of DT triggered apoptosis of GFP-positive cells (Supplementary Figure S1A). To specifically ablate striatonigral MSNs, we chose to drive the expression of the DTR-GFP construct under the control of a highly enriched striatonigral MSNs gene, Slc35d3 (Heiman et al, 2008; Lobo et al, 2006), using the BAC-based strategy (Supplementary Figure S1B). Transgenic mice were generated by injecting the recombined BAC into the pronuclei of hybrid C57Bl/ $6 \times$ CB1 F1 fertilized oocytes, which were then implanted into pseudopregnant females. The five $\operatorname{Slc} 35 d 3^{D T R-G F P}$ transgenic founders obtained (hereafter named DTR mice) were outbred with $\mathrm{C} 57 \mathrm{Bl} / 6$ mice. One founder did not breed correctly and was discarded from the study. In the four remaining lines, GFP-positive cells were detected in the striatum of $\mathrm{DTR}^{+}$mice (Supplementary Figure S1C) with a virtually indistinguishable expression pattern. Intrastriatal DTR-GFP protein levels assessed by western blotting were also similar in all the four lines (data not shown). We next determined in which cell type DTR-GFP was expressed. Retrograde fluorescent microbeads were injected into the $\mathrm{SNr}$ (Figure 1a), a main target of striatonigral MSNs. The colocalization of GFP-positive soma in the striatum with microbeads confirmed the expression of DTR-GFP by striatonigral MSNs (Figure 1a). The drastic reduction in GFP fluorescence after DT injection into the dorsal striatum of $\mathrm{DTR}^{+}$mice indicated an efficient ablation of DTR-GFPpositive cells in vivo (Figure 1b). The decrease in GFP fluorescence was observed in the rostro-caudal extent of the dorsal striatum while the ventral part (nucleus accumbens) was preserved (Supplementary Figure S2A). Time course analysis showed that the decrease in GFP fluorescence was progressive from day 1 to day 7; over day 7, the ablation was maximal and did not evolve anymore (Supplementary Figure S2B). All the following experiments were performed around 15 days after DT injection after stabilization of the ablation.

\section{Ablation of Striatonigral MSNs by DT Injection}

To test the specificity of striatonigral MSNs ablation, we analyzed markers of the different striatal populations using in situ hybridization, RT-qPCR, or immunohistochemistry 15 days after unilateral intrastriatal DT injection into the dorsal striatum. None of the markers examined was altered in the DT-injected side vs uninjected side in $\mathrm{DTR}^{-}$mice. $\mathrm{DTR}^{+}$mice showed strongly reduced $S P$ mRNA, a specific marker of striatonigral MSNs, while Enk mRNA, a specific marker of striatopallidal MSNs, was unchanged (Figure 1c and $\mathrm{d}$ ). Among the four lines, line 4 was selected for subsequent experiments, because it showed the highest decrease of $S P$ mRNA $(-66.3 \%$ vs uninjected side, $p<0.001)$. RT-qPCR analysis confirmed the significant reduction of $S P(-0.59$-fold $v s$ uninjected side, $p<0.01)$ and also showed a pronounced decrease in the expression of dopamine $\mathrm{D}_{1}$ receptor (Drd1a: -0.76 -fold $v s$ uninjected side, $p<0.001)$, another gene specifically expressed by striatonigral MSNs. In contrast, three genes enriched in striatopallidal MSNs (dopamine $\mathrm{D}_{2}$ receptor Drd2, Enk and Adenosine $\mathrm{A} 2{ }_{\mathrm{A}}$ receptor Adora2a) were not affected by DT injection, confirming the specificity of the ablation (Figure 1e). The levels of cAMP-regulated phosphoprotein32 (DARPP-32), a protein expressed in both populations of MSNs, were also significantly reduced by $39.2 \%$ (data not shown).

Knowing that MSNs project to the SNc (Gerfen, 1984), we examined TH mRNA levels in the SNc of DT-injected DTR ${ }^{+}$ mice and found that it was not altered by striatonigral MSNs ablation (data not shown). We then sought to determine the effect of intrastriatal DT on the two main targets of striatonigral and striatopallidal MSNs, the GABAergic neurons of the $\mathrm{SNr}$ and GP, respectively. We examined intraneuronal mRNA levels of the GABA synthesis enzyme GAD67 as an indirect index of GABA neuron activity. GAD67 mRNA expression was increased in the $\mathrm{SNr}$ of $\mathrm{DTR}^{+}$mice $(+18.2 \% v s$ uninjected side, $p<0.05)$, consistent with overactivity of this structure due to removal of the inhibitory control exerted by striatonigral MSNs (Figure 1f). In contrast, there was no change in GAD67 mRNA expression in the GP. Altogether, these data demonstrate that the $\mathrm{DTR}^{+}$transgenic mice are a reliable and effective model to specifically ablate striatonigral $v s$ striatopallidal MSNs and that this ablation has a functional impact on BG output.

The striatum contains three categories of GABAergic interneurons with specific cytochemical markers, parvalbumin, calretinin, or neuropeptide Y/NADPH-diaphorase, and one population of cholinergic interneurons expressing choline acetyltransferase (ChAT) (Kawaguchi, 1993). The density of neurons stained for parvalbumin, calretinin, or NADPH-diaphorase was unaffected by DT injection, whereas the density of ChAT-expressing neurons was decreased by $42.7 \%(p<0.01$; Figure 2$)$. To exclude downregulation of ChAT expression, we examined the effect of DT on another protein also specifically expressed by striatal cholinergic interneurons, the type A tyrosine kinase receptor (TrkA) (Holtzman et al, 1992). The density of TrkA-positive cells in the DT-injected side of $\mathrm{DTR}^{+}$mice was decreased to a similar level than ChAT-positive cells $(-41.2 \%$ vs uninjected side, $p<0.01$; Figure 2$)$. In DTR $^{-}$mice, DT injection did not affect ChAT-positive cells' density (uninjected side: $44.20 \pm 4.11$, injected side: $43.01 \pm 3.25, n=4 \mathrm{DTR}^{-}, p=0.83$ ), excluding a peculiar sensitivity of this population to DT compared with other striatal populations.

How one can explain the loss of cholinergic interneurons? Two possibilities: (1) DT injection mediates direct ablation of ChAT-positive neurons; and (2) loss of striatonigral MSNs in the dorsal striatum indirectly interferes with the survival of cholinergic interneurons. To distinguish between these two possibilities, we performed a series of control experiments. Using double staining experiments, we 
a

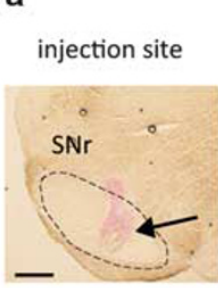

Striatum: GFP / microbeads

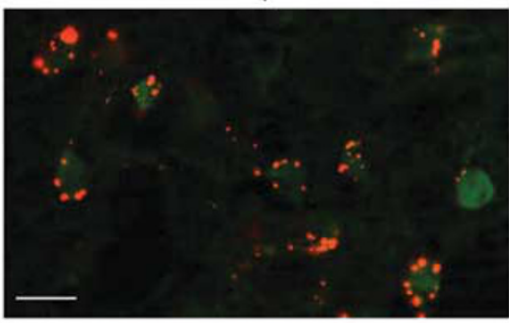

d

c

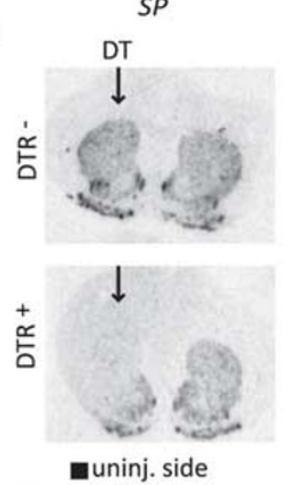

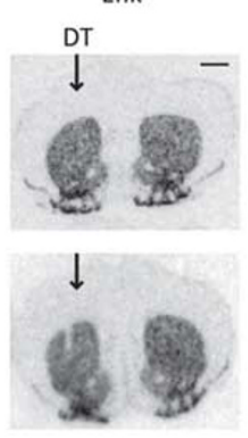

b

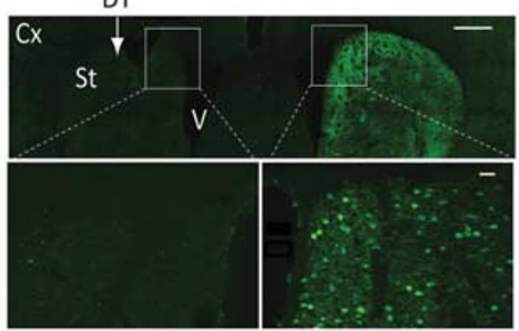

e
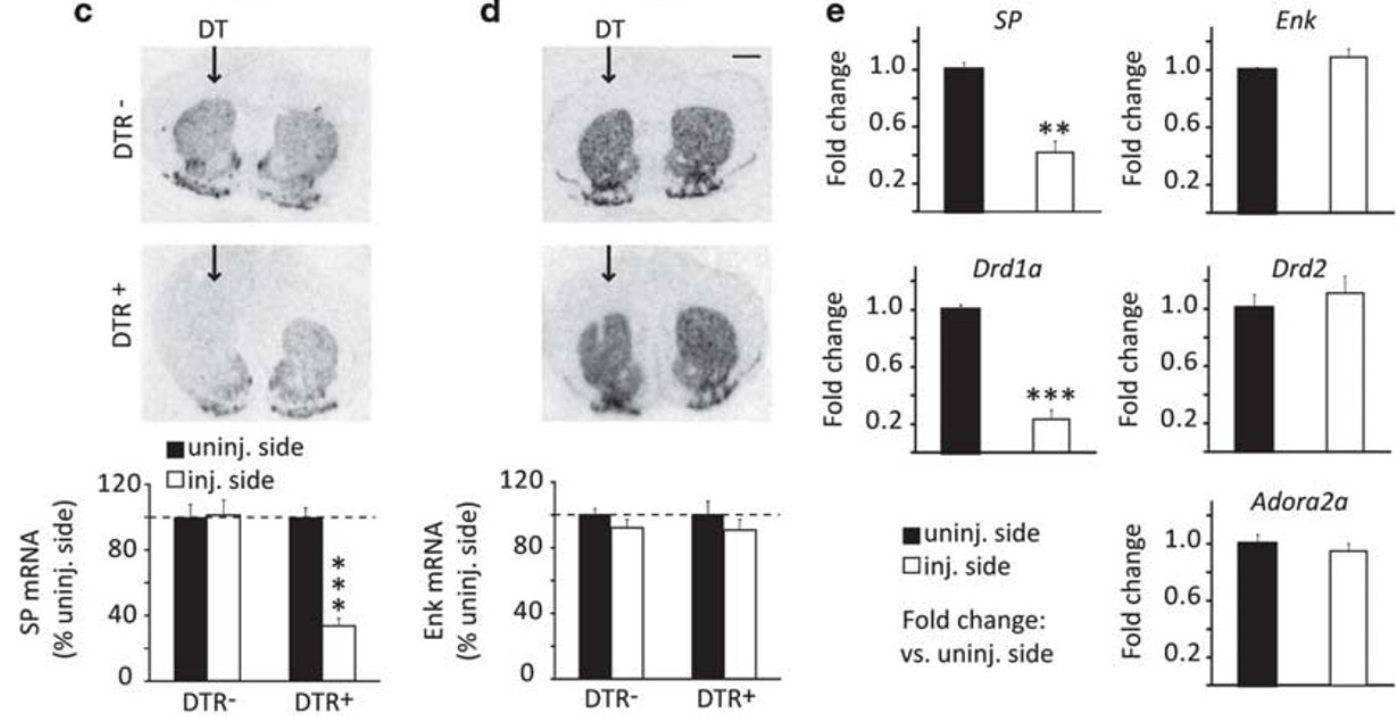

muninj. side 口inj. side

Fold change: vs. uninj. side
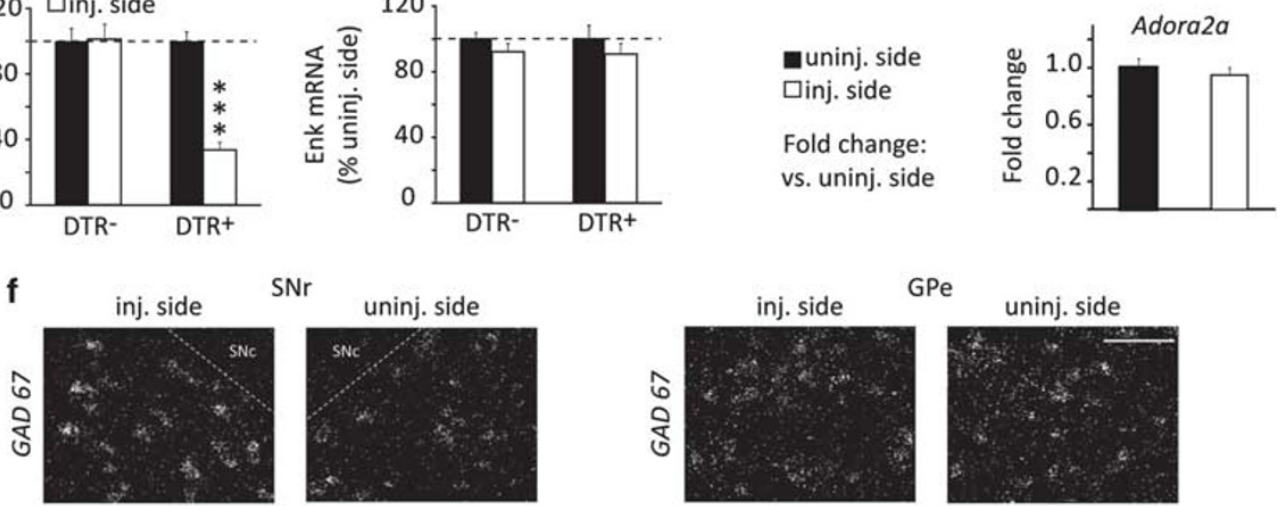

$\mathrm{SNr}$
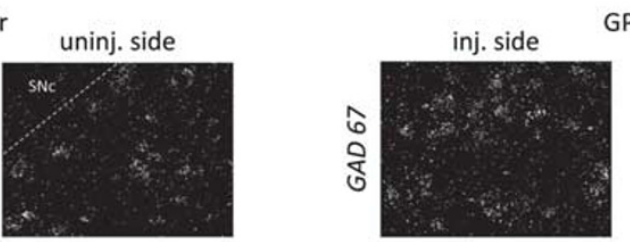

GPe
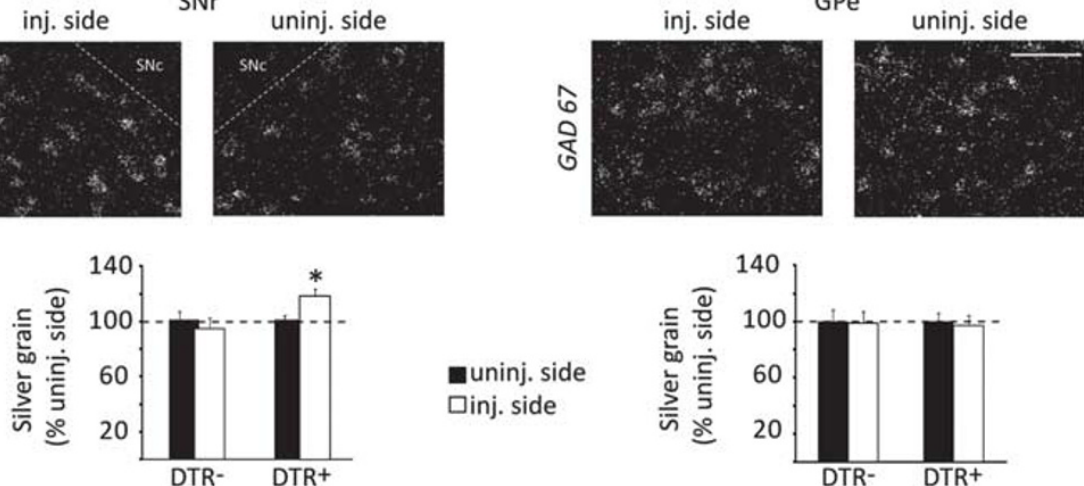

uninj. side 口inj. side

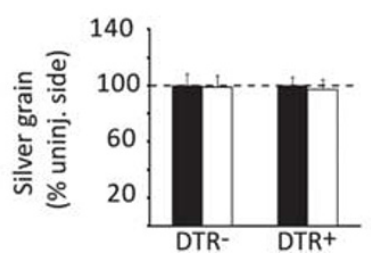

Figure I Selective expression of DTR-GFP in striatonigral neurons and impact of DT injection. (a) Left: injection site of fluorescent microbeads indicated by the arrow in the SNr. Scale bar, $200 \mu \mathrm{m}$. SNr: substantia nigra pars reticulata. Right: combined immunofluorescence detection of GFP-expressing striatal neurons and retrograde labeling of striatonigral MSNs 7 days after injection of fluorescent microbeads into the SNr of DTR ${ }^{+}$mice. The microbeads colocalized with GFP. Scale bar, $10 \mu \mathrm{m}$. (b) Striatal GFP immunodetection on a DTR ${ }^{+}$coronal brain section 7 days after unilateral DT injection into the striatum showing the loss of GFP expression in the injected side (left) compared with the uninjected side (right). Scale bars, top: $500 \mu \mathrm{m}$ and bottom: $20 \mu \mathrm{m}$. Cx: cortex, St: striatum, V: ventricle. (c, d) Radioactive in situ hybridizations and quantification of striatal SP (c) and Enk (d) mRNA levels I 5 days after unilateral DT injections into the striatum of DTR ${ }^{-}(n=6)$ and DTR ${ }^{+}(n=10)$ mice. Arrows indicate the injected side. Scale bar, I mm. Data are reported as optical density values and expressed as percentage \pm SEM. Student's $t$-test: **** $<0.00$ I vs uninjected side. (e) Quantitative RT-qPCR for genes specifically expressed in striatonigral (SP, Drd I a) or in striatopallidal MSNs (Enk, Drd2, Adora2a). Three DTR ${ }^{+}$mice were unilaterally injected with DT into the dorsal striatum, and the total RNA samples from this area were collected in the injected and uninjected side. Results were calculated for each sample relative to the expression of the endogenous reference gene, $\beta$-actin, and fold change was determined using the $2^{-\Delta \Delta C t}$ method. Student's $t$-test: $* * p<0.0$ I, **** $p<0.00$ I vs uninjected side. (f) Photomicrographs taken under dark-field epi-illumination illustrating intraneuronal GAD 67 mRNA levels in the SNr and GPe of DTR ${ }^{+}$mice, I 5 days after DT injections. Scale bar, $100 \mu \mathrm{m}$. Quantitative analysis of the number of silver grains per neurons in the SNr (left) $\left(n=5 \mathrm{DTR}^{-}\right.$and $\left.5 \mathrm{DTR}^{+}\right)$and GPe (right) $\left(n=5 \mathrm{DTR}^{-}\right.$and $\left.6 \mathrm{DTR}^{+}\right)$. Data are expressed as percentage \pm SEM. Student's t-test: $* p<0.05$ vs uninjected side.

performed a thorough examination of DTR expression in cholinergic interneurons. We found no colocalization between GFP and ChAT proteins in the striatum of DTR ${ }^{+}$ mice (Figure 3a). Using double in situ hybridization, we found no expression overlap between ChAT and DTR, whereas all $S P$-expressing cells were $D T R$ positive 
a
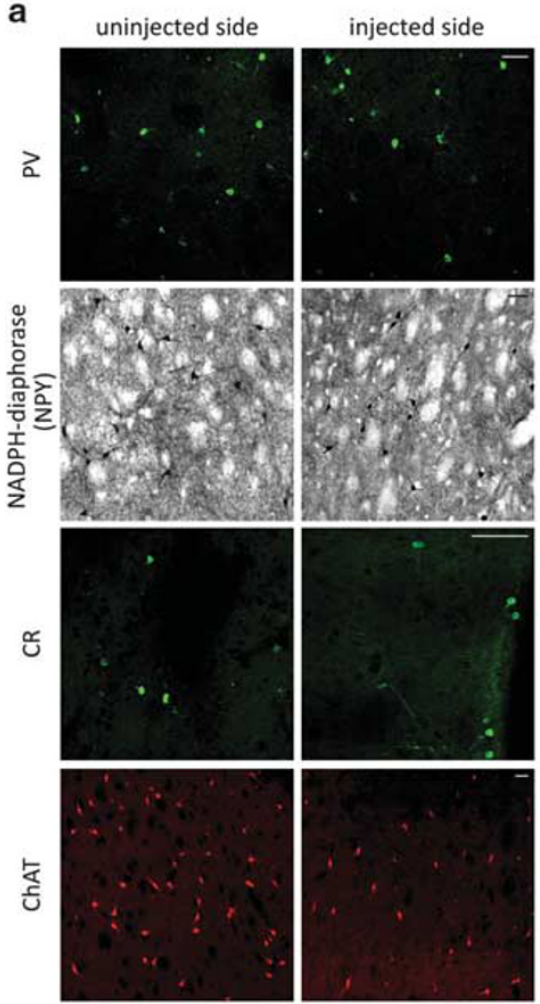

咅
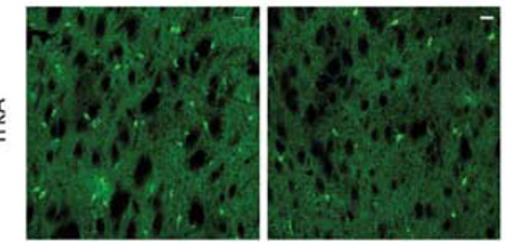

b
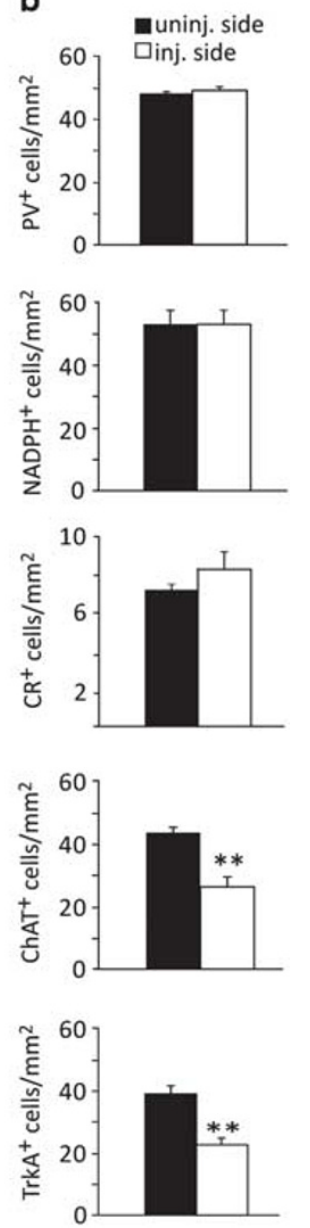

Figure 2 Consequences of striatonigral neuron ablation on striatal interneurons. (a) Coronal sections from DTR ${ }^{+}$mice unilaterally injected with DT were stained 15 days after injections for specific markers of GABAergic interneuron subpopulations (parvalbumin, PV; NADPH diaphorase to identify NPY interneurons, calretinin, CR) and for two markers of cholinergic interneurons (choline acetyltransferase, ChAT; type A tyrosine kinase receptor, TrKA). Scale bars, $50 \mu \mathrm{m}$. (b) Quantitative analyses illustrate the density of positive cells in the injected and uninjected sides $\left(n=4 \mathrm{DTR}^{+}\right)$. Data are expressed as mean \pm SEM. Student's $t$-test: *** $p<0.0$ I vs uninjected side.

(Figure 3b). To further confirm the lack of expression of DTR in cholinergic interneurons, we used single-cell RT-PCR. MSNs and cholinergic interneurons were identified by their distinctive morphological features and firing patterns recorded in cell-attached mode: MSNs have small soma and do not fire action potentials, whereas cholinergic interneurons have large soma and are the only striatal cells in slices that discharge spontaneously. ChAT mRNA was never detected in neurons expressing DTR $(n=9)$, and DTR mRNA was never detected in the neurons expressing ChAT $(n=8)$ (Figure $3 \mathrm{c})$. Altogether, these results demonstrate that the loss of cholinergic interneurons is not due to a direct effect of the toxin but is rather an indirect consequence of striatonigral MSNs ablation. This hypothesis is further strengthened by the time course analysis of cell loss we performed from 1 up to 22 days postDT injection. We found that the loss of ChAT-positive cells

was positively correlated to the loss of GFP fluorescence (reflecting MSNs ablation) and that a critical threshold of striatonigral MSNs ablation ( $>40 \%$ ) is required to impact cholinergic interneurons' viability (Figure $3 \mathrm{~d}$ ). Finally, as the nucleus accumbens is very similar to the dorsal striatum in terms of cellular composition, we examined the effect of a full ablation of striatonigral MSNs by injecting DT into both regions in the same mouse. Cholinergic interneurons in the dorsal striatum were significantly decreased $(p<0.001)$ while those located in the nucleus accumbens were not affected $(p=0.12)$, showing that cholinergic interneurons dependence on striatonigral MSNs is territory specific (Figure 3e).

\section{Behavioral Characterization}

Behavioral experiments were conducted on G3 mice $15 \pm 3$ days after intrastriatal DT injection in the dorsal striatum. Injections were made bilaterally except for LID (unilateral injection in the dopamine lesioned side). Animals included in the behavioral analyses were selected a posteriori based on marked reduction of SP mRNAs determined by in situ hybridization in the dorsal striatum $(-63.27 \pm 2.78 \%$, $n=27 \mathrm{DTR}^{+}$mice, $\left.p<0.001\right)$. In addition, we also quantified the level of SP mRNAs in the nucleus accumbens in animals used in the open-field and elevated plus maze tests and found no significant change $(-11.10 \pm 4.91 \%, n=10$ $\mathrm{DTR}+$ mice, $p=0.07)$. Performances of $\mathrm{DTR}^{+}$mice were compared with their control DTR ${ }^{-}$littermates.

Basal and cocaine-induced locomotion is altered in $D T$-injected $\mathrm{DTR}^{+}$mice. The dorsal striatum is involved in the regulation of motor activity and motor response to psychostimulants. We therefore examined basal locomotor activity and drug-induced locomotion after cocaine injection, a drug of abuse that increases locomotion by potentiating dopamine signaling. $\mathrm{DTR}^{+}$mice exhibited significantly reduced basal locomotion during the 60 -min test duration compared with $\mathrm{DTR}^{-}$mice $(p<0.05)$ (Figure $4 \mathrm{a}$ ). When acutely challenged with $15 \mathrm{mg} / \mathrm{kg}$ cocaine, both $\mathrm{DTR}^{-}$and $\mathrm{DTR}^{+}$mice showed an increased activity compared with their respective saline-injected group (DTR cocaine: $+134.90 \%$ vs $\mathrm{DTR}^{-}$saline, $p<0.001 ; \mathrm{DTR}^{+}$ cocaine: $+302.24 \%$ vs $\mathrm{DTR}^{+}$saline, $p<0.001$ ) (Figure $4 \mathrm{a}$ ). To be unbiased by the hypolocomotion of $\mathrm{DTR}^{+}$mice, the cocaine-induced locomotor activity was normalized for each genotype to the respective basal activity recorded in salineinjected mice. The locomotor response to cocaine observed in $\mathrm{DTR}^{+}$mice greatly exceeded the one observed in $\mathrm{DTR}^{-}$ mice $\left(+71.83 \% v s\right.$ DTR $^{-}$mice, $\left.p<0.01\right)$. To further confirm the hypersensitivity of $\mathrm{DTR}^{+}$mice to cocaine, we tested the effect of a lower dose of cocaine in another two groups of mice. A similar enhancement of the locomotor response to cocaine $5 \mathrm{mg} / \mathrm{kg}$ was found in $\mathrm{DTR}^{+}$mice $(+72.90 \%$ vs DTR $^{-}$mice, $p<0.05$; Figure $4 \mathrm{~b}$ ).

L-DOPA induced dyskinesia are strongly reduced in DT-injected $\mathrm{DTR}^{+}$mice. Dyskinesia is a common complication of L-DOPA pharmacotherapy in PD, affecting a large majority of patients within a few years from treatment onset. LID are associated with biochemical 
a

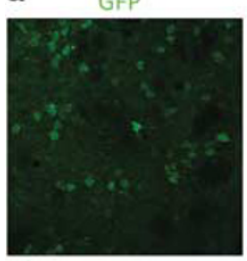

b
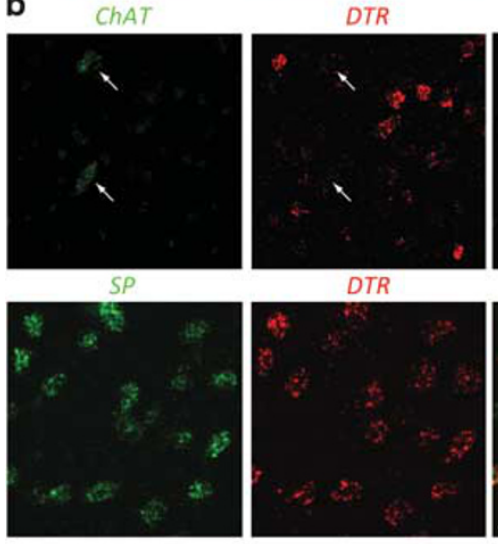

ChAT

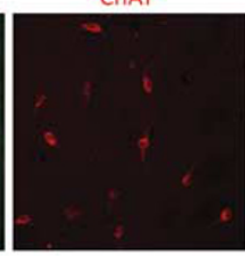

DTR

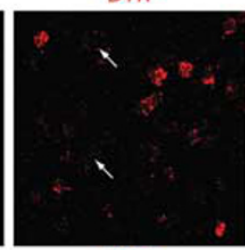

DTR e

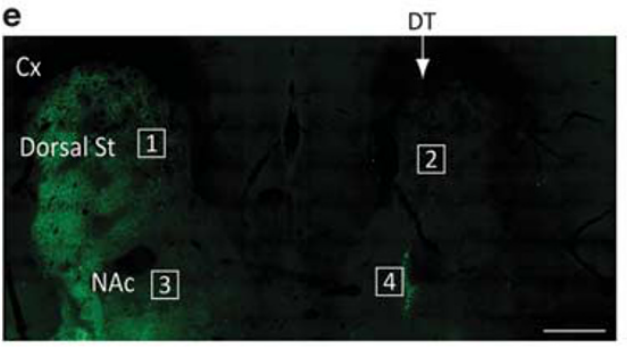

Merge

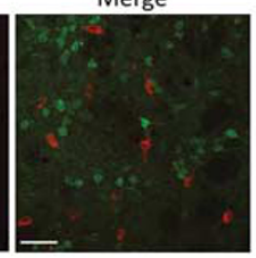

Merge
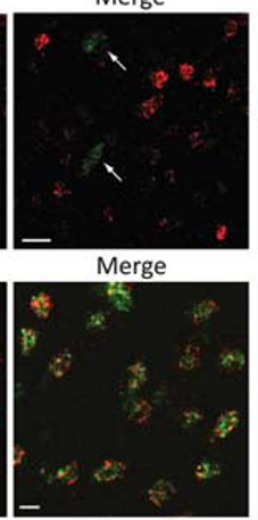

c

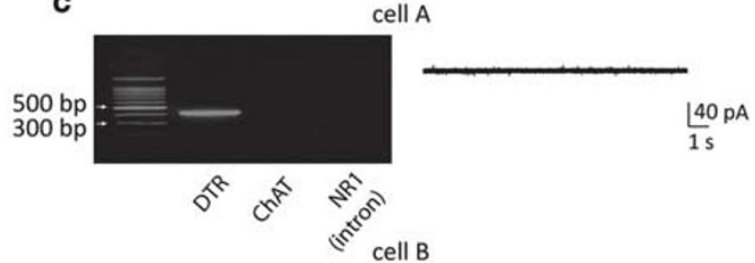

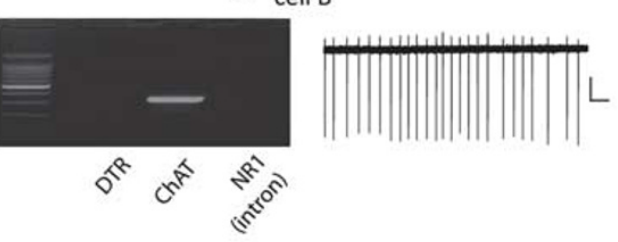

of cर

d
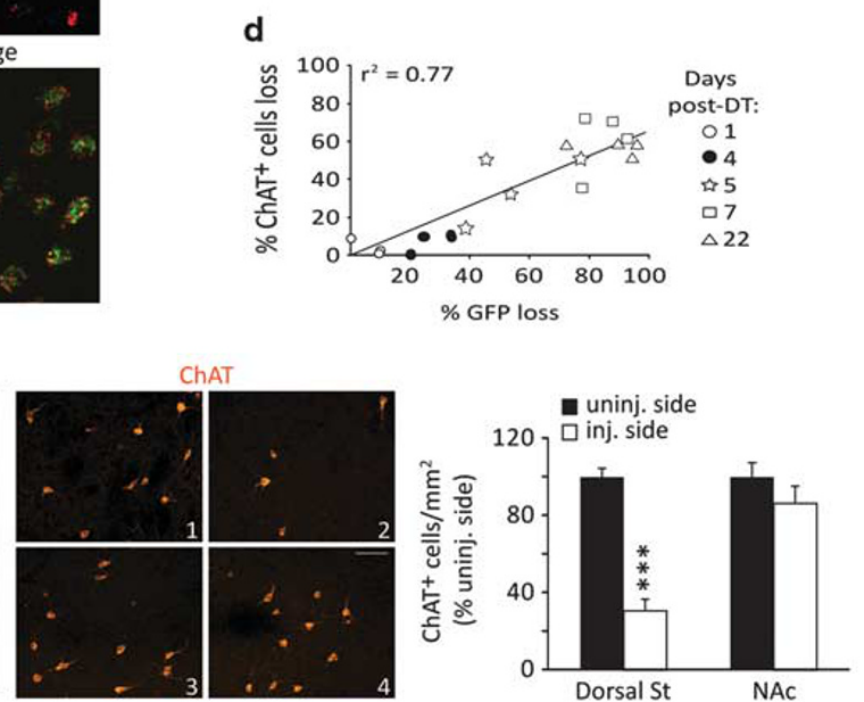

Figure 3 Absence of DTR expression in cholinergic interneurons and characteristics of cholinergic interneuron loss. (a) Double immunofluorescence labeling demonstrated that DTR, revealed by GFP expression (green), does not colocalize with choline acetyltransferase (ChAT) which labels the cholinergic interneurons (red). Scale bar, $50 \mu \mathrm{m}$. (b) Dual in situ hybridization showing that DTR (red) is not expressed in ChAT ${ }^{+}$cells (green, top, arrows) but colocalized with SP (green, bottom). Scale bars, $25 \mu \mathrm{m}$ (top) and $10 \mu \mathrm{m}$ (bottom). (c) Agarose gels of the single-cell RT-PCR products from two individual neurons whose electrical activity, recorded in cell-attached mode, is illustrated on the right. DTR-GFP mRNA (406 bp) is detected in a silent cell identified as MSN (top) but not in a spontaneous firing cell identified as cholinergic interneuron (bottom) that indeed expresses ChAT mRNA (323 bp). Cells are negative for the NRI gene intron showing no contamination of the cytoplasm by genomic DNA. (d) The percentage of cholinergic interneurons' (revealed by ChAT staining) and striatonigral MSNs' (revealed by GFP staining) loss, quantified at different time points after unilateral DT injection, is highly correlated. (e) GFP (left) and ChAT (right) immunodetection on a DTR ${ }^{+}$coronal brain section 15 days after unilateral DT injection into the dorsal striatum and the nucleus accumbens. Scale bars, left: $500 \mu \mathrm{m}$; right: $50 \mu \mathrm{m}$. Quantitative analyses illustrate the density of ChAT-positive cells in the dorsal striatum and the nucleus accumbens $\left(n=6 \mathrm{DTR}^{+}\right)$. Cx: cortex, St: striatum, NAc: nucleus accumbens. Data are expressed as percentage \pm SEM. Student's t-test: $* * * * 2<0.00$ I vs uninjected side.

alterations of the striatonigral pathway. We therefore examined whether LID expression was affected in DTinjected $\mathrm{DTR}^{+}$compared with $\mathrm{DTR}^{-}$mice rendered hemiparkinsonian by unilateral intranigral injection of 6-OHDA (Figure 5a). Strong and equivalent dopaminergic denervation of the striatum ipsilateral to the lesioned side was measured in both $\mathrm{DTR}^{-}(-95.5 \%$ vs uninjected side, $p<0.001)$ and $\mathrm{DTR}^{+}(-94.9 \%$ vs uninjected side, $p<0.001$ ) mice (Figure 5b). After a chronic 21 days of treatment with L-DOPA, DTR ${ }^{-}$mice exhibited robust AIMs, which were strongly reduced in $\mathrm{DTR}^{+}$mice both for dyskinesia $(-67.1 \%, p<0.001)$ and contralateral rotations $(-78.4 \%, \quad p<0.001)$ (Figure $5 \mathrm{c})$. The reduction of AIMs was observed at every time points over the 120-min scoring period following the last L-DOPA injection (repeated-measures ANOVA: genotype effect, $\mathrm{F}_{(1,26)}$
$=22.32, p<0.001 ;$ time effect, $\mathrm{F}_{(5,130)}=50.21, p<0.001$ genotype $\times$ time interaction, $\mathrm{F}_{(5,130)}=18.51, \quad p<0.001$; Figure $5 \mathrm{~d}$ ). These results provide direct evidence that striatonigral MSNs ablation can inhibit the expression of LID.

$D T$-injected $\mathrm{DTR}^{+}$mice show anxiolytic behavior. The limbic-related connections of the dorsal striatum raise the possibility of its involvement in emotional processing. To test this hypothesis, we assessed our transgenic mice in behavioral paradigms involving an anxiety component: the open field and the elevated plus maze. Mice display anxiety-related behaviors in open spaces; therefore, increased time spent in the central zone of the open field or in the open arms of the elevated plus maze is interpreted 

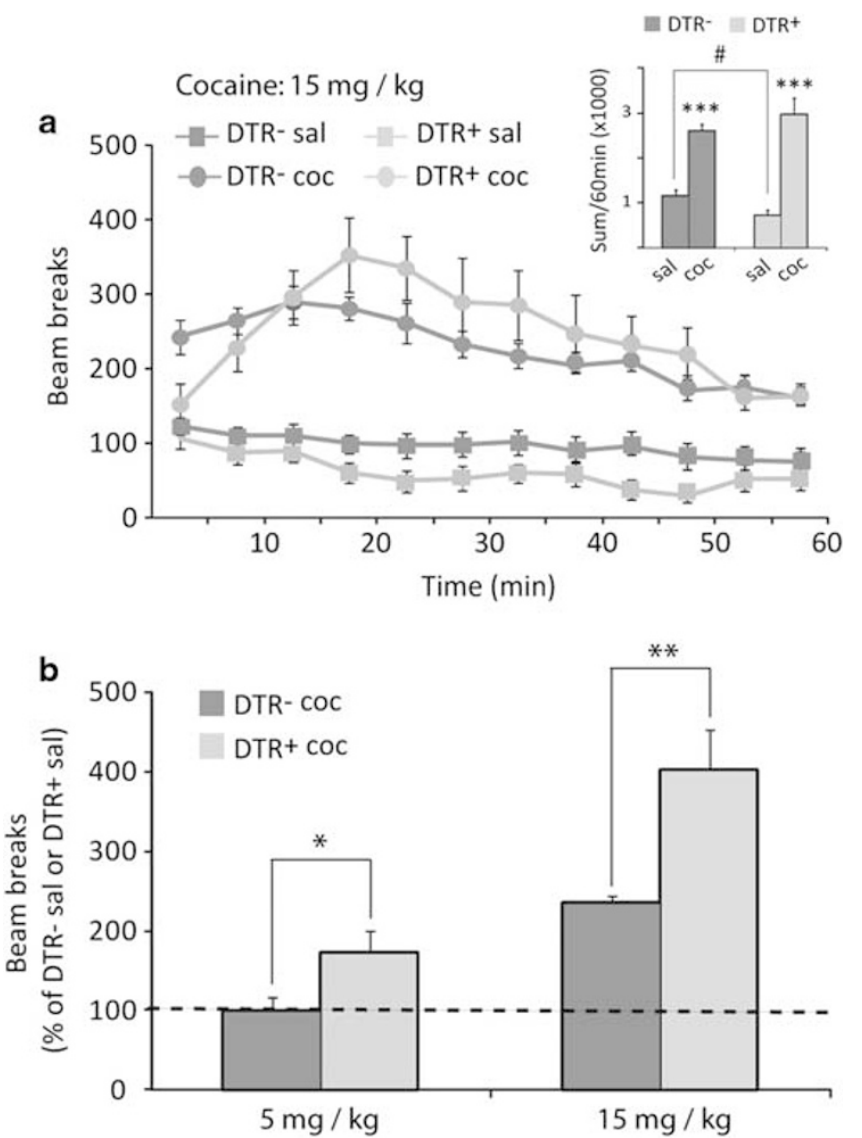

Figure 4 DT injection alters basal and cocaine-induced locomotion. (a) Line graphs illustrate the number of beam breaks in 5-min bins over a 60 -min period after saline or cocaine $(15 \mathrm{mg} / \mathrm{kg})$ injections for DTR $^{-}$( $n=14$ saline and 10 cocaine $)$ and DTR ${ }^{+}(n=9$ saline and 6 cocaine) mice. Inset shows the group means \pm SEM of total beam breaks for the 60 -min test period. Student's t-test: $* * * * * 00.001$ vs DTR $^{-}$sal or $\mathrm{DTR}^{+}$sal, \#p<0.05 vs DTR ${ }^{-}$sal. (b) Bar graphs comparing the locomotor response to two different doses of cocaine ( 5 and $15 \mathrm{mg} / \mathrm{kg}$ ). Data are the mean number of beam breaks measured during $60 \mathrm{~min}$ and are expressed for each genotype as the percentage \pm SEM of respective saline-treated mice $\left(5 \mathrm{mg} / \mathrm{kg}\right.$ group: DTR ${ }^{-}$mice, $n=12$ saline and 12 cocaine and DTR ${ }^{+}$mice, $n=5$ saline and 5 cocaine; $15 \mathrm{mg} / \mathrm{kg}$ group: DTR ${ }^{-}$mice, $n=14$ saline and 10 cocaine and DTR ${ }^{+}$mice, $n=9$ saline and 6 cocaine). Student's t-test: $*^{*} p<0.05$, *** $p<0.01$ vs DTR ${ }^{-}$coc.

as reduced anxiety. DT-injected $\mathrm{DTR}^{+}$mice showed marked increase in the time spent in the central zone of the open field $(p<0.05)$ as well as in the time spent $(p<0.001)$ and number of entries $(p<0.01)$ in the elevated plus maze (Figure 6). These changes reflect reduced anxiety and not a motor impairment as the total distance traveled during the 5-min test period was similar for $\mathrm{DTR}^{-}$and $\mathrm{DTR}^{+}$mice in the open-field (DTR ${ }^{-}: 2958.04 \pm 202.53 \mathrm{~mm}$, $n=17$; $\mathrm{DTR}^{+}: 2487.03 \pm 264.37 \mathrm{~mm}, n=10$; NS) and in the $\mathrm{EPM}\left(\mathrm{DTR}^{-}: 2094.1 \pm 96.7 \mathrm{~mm}, n=17 ; \mathrm{DTR}^{+}: 2014.8 \pm\right.$ $116.3 \mathrm{~mm}, n=10$; NS).

\section{DISCUSSION}

In the present study, we achieved inducible striatonigral MSNs' ablation by using cell-type specific expression of DTR and revealed three original results: (i) a region-specific a b
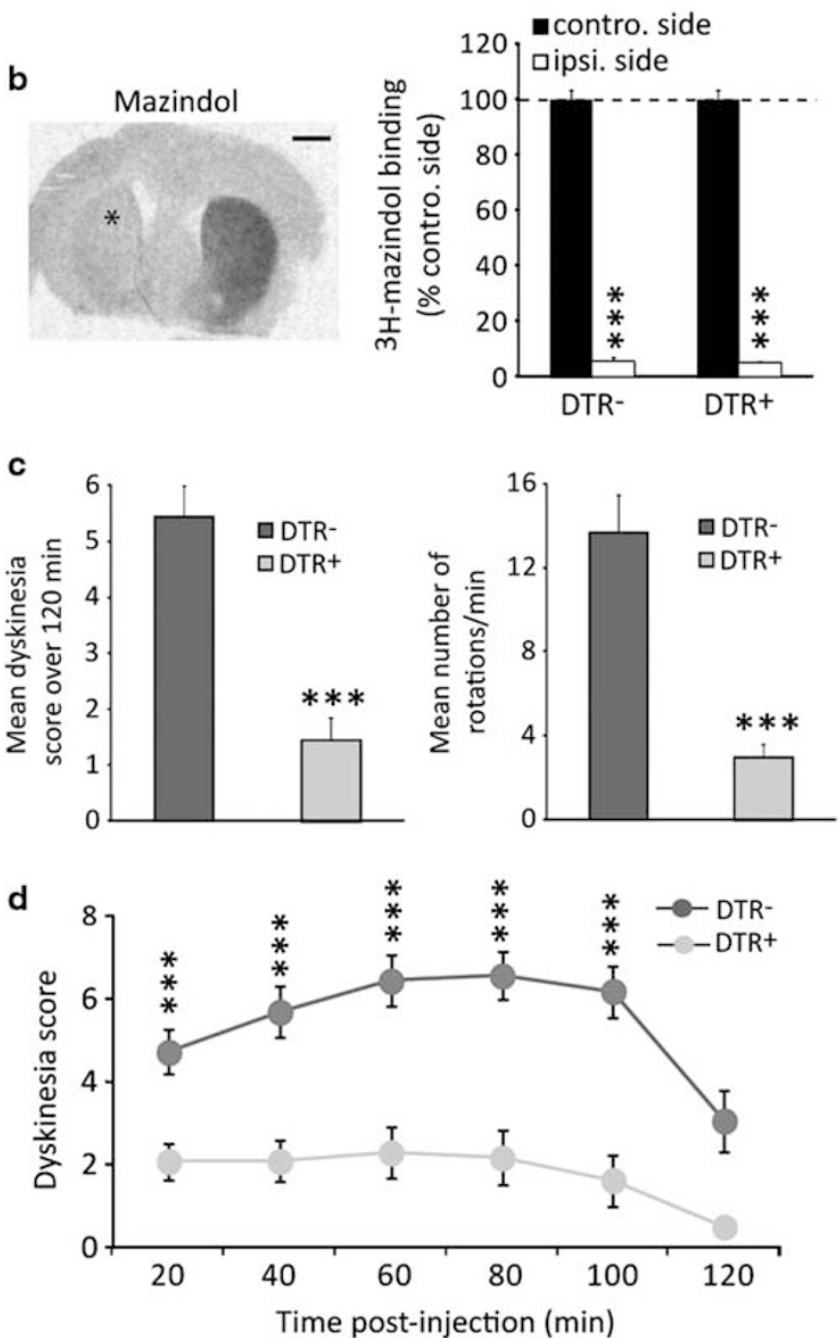

Figure 5 L-DOPA-induced dyskinesia are dramatically reduced after striatonigral neurons ablation. (a) Time course of L-DOPA-induced dyskinesia. (b) Autoradiographic image and quantitative analysis of ${ }^{3} \mathrm{H}$-mazindol binding showing the extensive loss of dopamine terminals in the striatum ipsilateral to the 6-OHDA injected side $\left.{ }^{*}\right)(n=16$ $\mathrm{DTR}^{-}$and $12 \mathrm{DTR}^{+}$). Data are expressed as the percentage \pm SEM. Student's t-test, $* * * * 00.001$ vs controlateral side. Scale bar, I mm. (c) Dyskinesia score (left; sum of the mean scores for axial, orolingual, and forelimb AIMs over 120 min; maximum 12) and locomotive AIM (right; mean number of contralateral rotations per minute over $120 \mathrm{~min}$ ) after L-DOPA injection on day 21 of chronic treatment $(n=16$ $\mathrm{DTR}^{-}$and $12 \mathrm{DTR}^{+}$). Data are expressed as mean \pm SEM. Student's $t-$ test, ${ }^{* * *} p<0.00$ I vs DTR ${ }^{-}$mice. (d) Time profile of axial, limb and orolingual dyskinesia scored every 20 min over a 120-min period after L-DOPA injection at day 21 in DTR ${ }^{-}(n=16)$ and DTR ${ }^{+}(n=12)$ mice. Data are reported as mean \pm SEM. Two-way RM ANOVA: Genotype: $F_{(1.26)}=22.32, p<0.001$; time: $F_{(5.130)}=50.21, p<0.001$; genotype $x$ time:, $F_{(5,130)}=\mid 8.51, p<0.001$, Holm-Sidak posttest: **** $p<0.001$. 
a

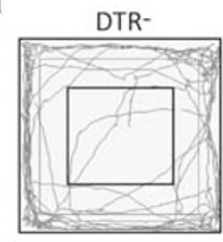

b

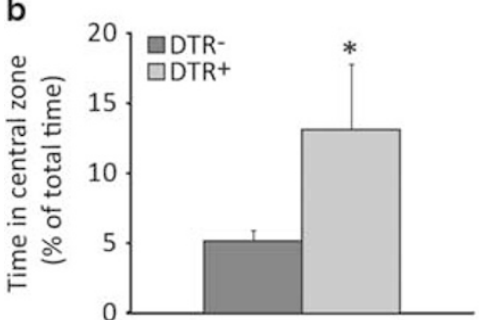

c

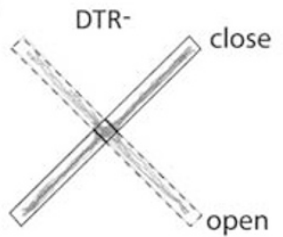

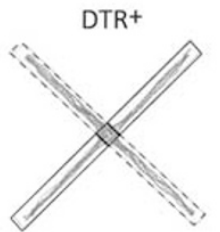

d

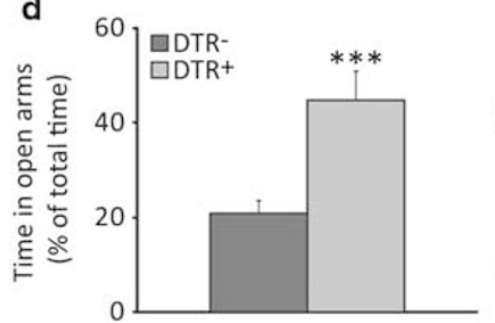

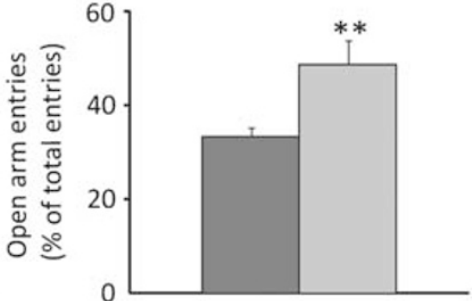

Figure 6 Anxiety is reduced after striatonigral MSNs' ablation. Representative paths $(a, c)$ and quantification showing the time spent in the central zone of the open field (b) as well as the time and the number of entries in the open arms of the elevated plus maze $(d)$ for DTR ${ }^{-}(n=17)$ and DTR ${ }^{+}(n=10)$ mice. Data are expressed as the percentage \pm SEM of the total time. Student's $t$-test: $* p<0.05$, , $^{*} p<0.0$ I, $* * * *<<0.00$ I vs DTR ${ }^{-}$mice.

regulation of cholinergic interneurons homeostasis by striatonigral MSNs, (ii) a causal implication of striatonigral MSNs in L-DOPA-induced dyskinesia, and (iii) the involvement of the dorsal striatum in the regulation of anxiety behavior.

We chose to express DTR under the control of the Slc35d3 gene promoter based on two studies using FACS (fluorescence-activated cell sorting) and TRAP (translating ribosome affinity purification) that identified Slc35d3 as the most striatonigral-enriched gene with a restricted expression to the striatum (Heiman et al, 2008; Lobo et al, 2006). Accordingly, intrastriatal injection of DT into the dorsal striatum triggered not only the elimination of a majority of striatonigral MSNs but also of a portion of cholinergic interneurons. We performed a series of experiments suggesting that the cholinergic loss, which occurred specifically in the dorsal but not in the ventral striatum, is the consequence of striatonigral MSNs' ablation. Another study, in which ablation of striatonigral MSNs is also obtained by DTR activation, reported no change in the number of striatal cholinergic interneurons after DT injection (Durieux et al, 2012). In this study, DTR expression in striatonigral MSNs is achieved by crossing iDTR mice (in which DTR expression is under the control of the ubiquitous Rosa26 promoter but is prevented by a loxPflanked STOP cassette) with $\mathrm{D}_{1}$-Cre mice. Knowing that transgene expression level is highly dependent on the promoter used to drive its expression, we can assume that DTR level is quite different in the two models. This might also explain the difference in the efficient DT dose between the two studies $(0.5 \mathrm{ng} / \mu \mathrm{l} v s 0.1 \mathrm{ng} / \mu \mathrm{l}$ in Durieux et al, 2012); indeed $0.1 \mathrm{ng} / \mu \mathrm{l}$ did not produce significant ablation in our model (not shown). Level of DTR expression might impact the degenerative process, as for instance the kinetics of striatonigral MSNs death and glial reactivity, and differently affect cholinergic interneurons. Reliance of striatal cholinergic survival on non-cell autonomous processes, involving for instance sonic hedgehog signaling from dopaminergic projections, was recently demonstrated in the adult brain (Gonzalez-Reyes et al, 2012). In our case, SP released by striatonigral MSNs might be a good candidate to support such pro-survival function as: (i) the presence of numerous SP positive axonal terminals making synaptic contact with dendrites of cholinergic neurons suggests an intimate relationship between these two populations (Bolam et al, 1986), (ii) SP biological functions are mediated by the NK1 receptor, which is almost exclusively expressed by cholinergic interneurons in the striatum (Elde et al, 1990; Gerfen, 1991), and (iii) NK1 receptor activation triggers pro-survival pathways crucial for the maintenance of some neuronal populations (Chu et al, 2011). The differential effects of DT in the striatum and nucleus accumbens open interesting questions and suggest that the cholinergic interneurons have distinct properties in each territory. Further experiments, which are beyond the scope of this study, will be necessary to investigate this region-specific interaction between striatonigal MSNs and cholinergic interneurons.

Our behavioral data showing reduced locomotion in DT-injected DTR ${ }^{+}$mice confirm the BG model of the direct pathway promoting movement and are consistent with recent studies reporting that optogenetic activation or specific ablation of striatonigral MSNs enhances and reduces locomotion, respectively (Durieux et al, 2012; Kravitz et al, 2010). The increase in GAD 67 mRNA level in the SNr of DT-injected mice further supports the view that hypolocomotion results from overactive BG outflow subsequent to removal of the inhibitory influence exerted by striatonigral MSNs. In contrast to basal locomotion, our transgenic mice unexpectedly displayed an increase in cocaine-induced activity. Indeed, previous studies reported decreased locomotor response to acute injection of psychostimulants after specifically inhibiting synaptic transmission in striatonigral MSNs (Hikida et al, 2010) or ablating these neurons in the striatum (Durieux et al, 2012). Differences in the psychostimulant used or the area of the striatum targeted is unlikely to account for such a discrepancy, suggesting that our phenotype might not be the direct consequence of striatonigral damage. Interestingly, an increased sensitivity to acute cocaine has been 
reported after elimination of cholinergic cells in the dorsal striatum or the nucleus accumbens (Hikida et al, 2001; Sano et al, 2003), suggesting that the loss of striatal cholinergic interneurons rather than ablation of striatonigral MSNs might be responsible for the potentiation of cocaineinduced locomotor response.

LID, a major side effect of chronic L-DOPA treatment in $\mathrm{PD}$, are associated with molecular changes occurring specifically in striatonigral MSNs (Santini et al, 2009). Our data, showing that striatonigral MSNs ablation prevents the development of LID, provide direct evidence for the causal role of these neurons in LID. This antidyskinetic effect is in agreement with the one obtained after genetic inactivation of DARPP-32 in striatonigral MSNs (Bateup et al, 2010). The shift in ERK activation from MSNs to cholinergic interneurons described after long-term exposure to L-DOPA (7 weeks) suggests that the cholinergic interneurons might also be involved in LID expression (Ding et al, 2011). Here the beneficial effect of striatonigral MSNs ablation on LID was observed as early as 7 days post-L-DOPA treatment (not shown), a time where ERK activation in cholinergic interneurons is not yet turned on (Ding et al, 2011). Thus our results support a primary role of striatonigral MSNs in the development of dyskinesia and also suggest that therapeutic strategies based on manipulation of dopamine-dependent signaling in the striatum should target the striatonigral MSNs for an efficient clinical approach to prevent LID.

Accumulating evidence suggest that the dorsal striatum might also be involved in emotional and motivational processing (Balleine et al, 2007). Here we found that DTinjected $\mathrm{DTR}^{+}$mice exhibited reduced anxiety in the openfield and elevated plus maze tests. Considering that SP is of relevance in the regulation of emotional states, including anxiety-related behavior (Ebner and Singewald, 2006), and that striatonigral MSNs are the main source of SP in the striatum, our result suggest a role for striatal SP in the regulation of anxiety. Consistent with the anxiolytic effect of striatonigral MSNs ablation, pharmacological blockade or genetic deletion of NK1 receptors produced anxiolytic-like effects (File, 1997; Santarelli et al, 2001). As NK1 receptors expressed by cholinergic interneurons are important mediators of SP action in the striatum, the loss of this striatal population in our model is likely to accentuate the anxiolytic effect. SP is widely distributed in the brain and the SP-sensitive areas commonly implicated in the control of anxious states are part of the limbic system (Davis et al, 2010). Although the dorsal striatum has limbic connections through the dopamine system (Haber et al, 2000), its involvement in anxiety behavior is quite novel and highlights the plurality of neuronal substrates underlying this behavior. Interestingly, dynorphin, another peptide specifically expressed by striatonigral MSNs, has been implicated in anxiety and might thus participate to the reduced anxiety exhibited by the DT-injected transgenic mice (Schwarzer, 2009; Van't Veer and Carlezon, 2013).

Altogether, our data reveal an intimate relationship between striatonigral MSNs and cholinergic interneurons in the dorsal striatum and provide experimental evidence for the implication of these populations not only in dopamine-dependent motor behaviors but also in the control of anxiety, emphasizing the functional overlap between the dorsal striatum and the nucleus accumbens.

\section{FUNDING AND DISCLOSURE}

The authors declare no conflict of interest.

\section{ACKNOWLEDGEMENTS}

This work was supported by CNRS, Aix-Marseille Université, Fondation de France, Fédération pour la Recherche sur le Cerveau. D.R. was supported by a grant from the Ministry of Education and Research and France Parkinson. We thank A. de Kerchove d'Exaerde for his help in the BAC transgenesis and single-cell RT-PCR experiments, A. Moqrich for helpful discussion and comments on the manuscript, and A. Reynders for her critical comments on the manuscript. We also thank the animal and imaging facilities of the IBDM.

\section{REFERENCES}

Albin RL, Young AB, Penney JB (1989). The functional anatomy of basal ganglia disorders. Trends Neurosci 12: 366-375.

Balleine BW, Delgado MR, Hikosaka O (2007). The role of the dorsal striatum in reward and decision-making. J Neurosci 27: 8161-8165.

Bateup HS, Santini E, Shen W, Birnbaum S, Valjent E, Surmeier DJ et al (2010). Distinct subclasses of medium spiny neurons differentially regulate striatal motor behaviors. Proc Natl Acad Sci USA 107: 14845-14850.

Bertran-Gonzalez J, Bosch C, Maroteaux M, Matamales M, Herve D, Valjent E et al (2008). Opposing patterns of signaling activation in dopamine D1 and D2 receptor-expressing striatal neurons in response to cocaine and haloperidol. J Neurosci 28: 5671-5685.

Beurrier C, Lopez S, Revy D, Selvam C, Goudet C, Lherondel M et al (2009). Electrophysiological and behavioral evidence that modulation of metabotropic glutamate receptor 4 with a new agonist reverses experimental parkinsonism. FASEB J 23: 3619-3628.

Bolam JP, Ingham CA, Izzo PN, Levey AI, Rye DB, Smith AD et al (1986). Substance P-containing terminals in synaptic contact with cholinergic neurons in the neostriatum and basal forebrain: a double immunocytochemical study in the rat. Brain Res 397: 279-289.

Bolam JP, Wainer BH, Smith AD (1984). Characterization of cholinergic neurons in the rat neostriatum. A combination of choline acetyltransferase immunocytochemistry, Golgi-impregnation and electron microscopy. Neuroscience 12: 711-718.

Cenci MA (2007). Dopamine dysregulation of movement control in L-DOPA-induced dyskinesia. Trends Neurosci 30: 236-243.

Chu JM, Chen LW, Chan YS, Yung KK (2011). Neuroprotective effects of neurokinin receptor one in dopaminergic neurons are mediated through Akt/PKB cell signaling pathway. Neuropharmacology 61: 1389-1398.

Davis M, Walker DL, Miles L, Grillon C (2010). Phasic vs sustained fear in rats and humans: role of the extended amygdala in fear vs anxiety. Neuropsychopharmacology 35: 105-135.

DeLong MR (1990). Primate models of movement disorders of basal ganglia origin. Trends Neurosci 13: 281-285.

Ding Y, Won L, Britt JP, Lim SA, McGehee DS, Kang UJ (2011). Enhanced striatal cholinergic neuronal activity mediates L-DOPAinduced dyskinesia in parkinsonian mice. Proc Natl Acad Sci USA 108: $840-845$. 
Durieux PF, Bearzatto B, Guiducci S, Buch T, Waisman A, Zoli M et al (2009). D2R striatopallidal neurons inhibit both locomotor and drug reward processes. Nat Neurosci 12: 393-395.

Durieux PF, Schiffmann SN, de Kerchove dA (2012). Differential regulation of motor control and response to dopaminergic drugs by $\mathrm{D} 1 \mathrm{R}$ and $\mathrm{D} 2 \mathrm{R}$ neurons in distinct dorsal striatum subregions. EMBO J 31: 640-653.

Ebner K, Singewald N (2006). The role of substance P in stress and anxiety responses. Amino Acids 31: 251-272.

Elde R, Schalling M, Ceccatelli S, Nakanishi S, Hokfelt T (1990). Localization of neuropeptide receptor mRNA in rat brain: initial observations using probes for neurotensin and substance $\mathrm{P}$ receptors. Neurosci Lett 120: 134-138.

Ferguson SM, Eskenazi D, Ishikawa M, Wanat MJ, Phillips PE, Dong Y et al (2011). Transient neuronal inhibition reveals opposing roles of indirect and direct pathways in sensitization. Nat Neurosci 14: 22-24.

File SE (1997). Anxiolytic action of a neurokinin1 receptor antagonist in the social interaction test. Pharmacol Biochem Behav 58: 747-752.

Gerfen CR (1984). The neostriatal mosaic: compartmentalization of corticostriatal input and striatonigral output systems. Nature 311: 461-464.

Gerfen CR (1991). Substance P (neurokinin-1) receptor mRNA is selectively expressed in cholinergic neurons in the striatum and basal forebrain. Brain Res 556: 165-170.

Gerfen CR, Engber TM, Mahan LC, Susel Z, Chase TN, Monsma FJ Jr. et al (1990). D1 and D2 dopamine receptor-regulated gene expression of striatonigral and striatopallidal neurons. Science 250: 1429-1432.

Gonzalez-Reyes LE, Verbitsky M, Blesa J, Jackson-Lewis V, Paredes D, Tillack K et al (2012). Sonic hedgehog maintains cellular and neurochemical homeostasis in the adult nigrostriatal circuit. Neuron 75: 306-319.

Graybiel AM (2000). The basal ganglia. Curr Biol 10: R509-R511.

Haber SN, Fudge JL, McFarland NR (2000). Striatonigrostriatal pathways in primates form an ascending spiral from the shell to the dorsolateral striatum. J Neurosci 20: 2369-2382.

Heiman M, Schaefer A, Gong S, Peterson JD, Day M, Ramsey KE et al (2008). A translational profiling approach for the molecular characterization of CNS cell types. Cell 135: 738-748.

Hikida T, Kaneko S, Isobe T, Kitabatake Y, Watanabe D, Pastan I et al (2001). Increased sensitivity to cocaine by cholinergic cell ablation in nucleus accumbens. Proc Natl Acad Sci USA 98: 13351-13354.

Hikida T, Kimura K, Wada N, Funabiki K, Nakanishi S (2010). Distinct roles of synaptic transmission in direct and indirect striatal pathways to reward and aversive behavior. Neuron 66: 896-907.

Hikida T, Yawata S, Yamaguchi T, Danjo T, Sasaoka T, Wang Y et al (2013). Pathway-specific modulation of nucleus accumbens in reward and aversive behavior via selective transmitter receptors. Proc Natl Acad Sci USA 110: 342-347.

Holtzman DM, Li Y, Parada LF, Kinsman S, Chen CK, Valletta JS et al (1992). p140trk mRNA marks NGF-responsive forebrain neurons: evidence that trk gene expression is induced by NGF. Neuron 9: 465-478.

Kawaguchi Y (1993). Physiological, morphological, and histochemical characterization of three classes of interneurons in rat neostriatum. J Neurosci 13: 4908-4923.

Kravitz AV, Freeze BS, Parker PR, Kay K, Thwin MT, Deisseroth K et al (2010). Regulation of parkinsonian motor behaviours by optogenetic control of basal ganglia circuitry. Nature 466: 622-626.

Lena C, de Kerchove D'E, Cordero-Erausquin M, le NN, del MA-J, Changeux JP (1999). Diversity and distribution of nicotinic acetylcholine receptors in the locus ceruleus neurons. Proc Natl Acad Sci USA 96: 12126-12131.

Livak KJ, Schmittgen TD (2001). Analysis of relative gene expression data using real-time quantitative $\mathrm{PCR}$ and the 2(-Delta Delta C(T)) method. Methods 25: 402-408.

Lobo MK, Covington HE III, Chaudhury D, Friedman AK, Sun H, mez-Werno D et al (2010). Cell type-specific loss of BDNF signaling mimics optogenetic control of cocaine reward. Science 330: $385-390$.

Lobo MK, Nestler EJ (2011). The striatal balancing act in drug addiction: distinct roles of direct and indirect pathway medium spiny neurons. Front Neuroanat 5: 41.

Lobo MK, Karsten SL, Gray M, Geschwind DH, Yang XW (2006). FACS-array profiling of striatal projection neuron subtypes in juvenile and adult mouse brains. Nat Neurosci 9: 443-452.

Lundblad M, Picconi B, Lindgren H, Cenci MA (2004). A model of L-DOPA-induced dyskinesia in 6-hydroxydopamine lesioned mice: relation to motor and cellular parameters of nigrostriatal function. Neurobiol Dis 16: 110-123.

Nishizawa K, Fukabori R, Okada K, Kai N, Uchigashima M, Watanabe $\mathrm{M}$ et al (2012). Striatal indirect pathway contributes to selection accuracy of learned motor actions. J Neurosci 32: 13421-13432.

Paxinos G, Franklin KBJ (2001). The Mouse Brain in Stereotaxic Coordinates, 2nd edn. Academic Press: San Diego.

Salin P, Manrique C, Forni C, Kerkerian-Le GL (2002). High-frequency stimulation of the subthalamic nucleus selectively reverses dopamine denervation-induced cellular defects in the output structures of the basal ganglia in the rat. J Neurosci 22: 5137-5148.

Sano H, Yasoshima Y, Matsushita N, Kaneko T, Kohno K, Pastan I et al (2003). Conditional ablation of striatal neuronal types containing dopamine D2 receptor disturbs coordination of basal ganglia function. J Neurosci 23: 9078-9088.

Santarelli L, Gobbi G, Debs PC, Sibille ET, Blier P, Hen R et al (2001). Genetic and pharmacological disruption of neurokinin 1 receptor function decreases anxiety-related behaviors and increases serotonergic function. Proc Natl Acad Sci USA 98: 1912-1917.

Santini E, Alcacer C, Cacciatore S, Heiman M, Herve D, Greengard P et al (2009). L-DOPA activates ERK signaling and phosphorylates histone $\mathrm{H} 3$ in the striatonigral medium spiny neurons of hemiparkinsonian mice. J Neurochem 108: 621-633.

Schwarzer C (2009). 30 years of dynorphins-new insights on their functions in neuropsychiatric diseases. Pharmacol Ther 123: 353-370.

Smith Y, Bevan MD, Shink E, Bolam JP (1998). Microcircuitry of the direct and indirect pathways of the basal ganglia. Neuroscience 86: 353-387.

Tai LH, Lee AM, Benavidez N, Bonci A, Wilbrecht L (2012). Transient stimulation of distinct subpopulations of striatal neurons mimics changes in action value. Nat Neurosci 15: 1281-1289.

Van't Veer A, Carlezon WA (2013). Role of kappa-opioid receptors in stress and anxiety-related behavior. Psychopharmacology (Berl) 229: 435-452.

Yawata S, Yamaguchi T, Danjo T, Hikida T, Nakanishi S (2012). Pathway-specific control of reward learning and its flexibility via selective dopamine receptors in the nucleus accumbens. Proc Natl Acad Sci USA 109: 12764-12769.

Supplementary Information accompanies the paper on the Neuropsychopharmacology website (http://www.nature.com/npp) 